\title{
NEW BACKUP ROLL GRADE FOR SKIN PASS MILLS*
}

Gerd Weyand ${ }^{1}$

Klaus Habitzki²

Peter Heisterkamp ${ }^{3}$

\begin{abstract}
Gontermann-Peipers GmbH (GP) Germany developed a new, high alloyed steel grade for the manufacturing of back-up rolls. The advanced GP double pour casting processes provide highest flexibility in being quite open in rolls work layer chemistry and hence microstructure with no influence on core respectively neck properties. GP took the process advantage to provide a brand new back-up roll grade with remarkably reduced roll wear while operating with textured work rolls. In the meantime several successful trials have been made with this new roll grade on different Skin Pass Mills. As a result the performance of back-up roll and thus availability of mill will be improved while specific costs for mill will drop. This quite new back-up roll grade has recently been launched. As next step increasing the field of applications is under progress.
\end{abstract}

Keywords: Back-up roll; Cold rolling mill; Skin pass mill; Wear; Double poured roll. 


\section{INTRODUCTION}

The quality requirements on cold rolled steel strip increase steadily and hence all the process parameters need to be improved as well. Surface appearance, flatness, deep-drawing behavior or mechanical properties of cold rolled strip are only some of the main requirements which are influenced, among others, by the rolling process. Uniformity and constancy of roll gap is an important control variable for flatness, and beside the hydraulic / electric roll gap adjusting controls the rolls itself with their shape and crown have some major impact. To maintain the profile of the backup roll as long as possible, while both minimizing the impact on roll gap geometry and minimizing the negative impact on contact load distribution, is the subject of the invented roll grade and accordingly of this report.

Based on the knowledge, experience and advantage of double poured casting in general and with the available capabilities of static as well as spin casting in a wide dimensional range, the field for investigations on different alloys and hereby material properties is wide open. Most recently invented backup roll grade, representing in evolution one the reduced wear in cold rolling applications, is a highly Chromium (Cr), Molybdenum (M) and Vanadium (V) alloyed steel. It received the GontermannPeipers (GP) brand name ASTI90X. The comparison of this all new backup roll grade with well-known and established backup roll grades, underline the impact of alloying materials. Minimized wear on this backup roll grade provide requested roll profile constancy.

Beside the technical impact on the finished product, the main factors to be considered are the reliability in mill operation, and the performance of the rolls as well as of the mill. Equally distributed load in the contact area between backup roll and work/intermediate roll increase the safety factor, and longer campaigns reduce the downtime of the mill as well as the workload on the available roll grinder. Reduction of the total cost of ownership (TCO) will be well received by the mill and financial management. Referring to the environmental aspects of global economy and worldwide competition, it is helpful for the mill to achieve high quality requirements and even limit the cost for production.

\section{COLD ROLLING OF STEEL}

Products made from cold rolled steel strip are everywhere and every day in our life. Some are clear and visible and some are not or almost never visible. However, the variance of required properties of the material is as big as the field of applications. Surface appearance like high-gloss or mat will dignify the visible finished product. Other products of daily use, like the cars, hide their rolled surface under a painting, but the rolled surface roughness and structure has impact on the visual appearance of the painted surface and hence on the appearance of the perfect product. Strip flatness is sometimes very important for further processing of the material. In addition to flatness and the surface appearance of visible products there are also mechanical properties which need to be controlled during the cold rolling process. Deep-drawing for beverage cans for example require the right surface quality as well as the right deformation behavior. Improvements in the rolling and deep-drawing process over the past 30 years reduced the weight of steel cans by about $30 \%$ [1], an important step in the ongoing competition with aluminum cans. Beside the mechanical 
properties and surface appearance even the economic and ecologic aspect is of essence for manufacturers of cold rolled strip.

\subsection{Skin Pass Rolling}

To fulfill the requirements in terms of material strength, deformation properties and surface structure (for example for painting or deep-drawing), the skin pass rolling is essential. Compared to the typical reduction of the strip in a tandem mill, the amount of reduction in skin pass process is quite low and commonly in the range of 0.1 to $1.5 \%$ (exceptionally up to $3 \%$ ). The process step of skin pass rolling is at the very end within the steel processing chain and finally provides the mechanical, surface and geometrical properties required for various applications.

If a defined strip surface structure is required, the Skin Pass Mill is working with a textured work roll. The roll surface structure is transferred to the cold rolled annealed or galvanized strip. Typical roughness of the work rolls is in the range of $70 \mu$ lnch $200 \mu \mathrm{lnch}$, but even can be up to $400 \mu \mathrm{Inch}$. Beside roughness (Ra) even the amount of peaks (Rpc) on the work roll is an important quality factor and need to be controlled by the texturing process. Texturing of the work rolls is a defined surface treatment and most commonly done by Electric Discharge Texturing (EDT) or shot blasting. Other processes like Laser Texturing or PRETEX® (Salzgitter AG) are applied today as well. The roughness and peak count of the work roll surface is depending on further processing of strip material. In most cases the textured rolls will finally be chromium plated before entering the mill.

Work roll campaign length in a skin pass mill is, among others, driven by the constancy of strip profile as well as by the surface structure like roughness or peak count. Inventions and improvements on more constant conditions with the work rolls are going on in order to improve reliability and effectiveness of the process. A high mill availability rate is one of several key factors for best economic operation. Decreasing the amount of expensive consumables, like rolls and decreasing of operating costs are ever valid targets in global steel market

\subsection{Dry and Wet Skin Pass Rolling}

The Skin Pass Rolling provides the finished surface of the steel. Clean conditions for the mill and best possible prevention of dirt in the roll gap are required. In many cases the mill is working successful with wet skin passing agents which even keep the dirt away from strip, serves for roll gap lubrication and thus reduces roll forces. However, some steel strips for automotive parts, as well as many parts for household appliance are required to be supplied without using wet skin pass process. The dry skin passing demand special efforts to fulfill the high quality requirements but the technical equipment is available and provided by the mill builder. Depending on the target of the mill, the skin pass process is either wet or dry. It must also be considered that the roughness transfer rate from the work roll to the strip is higher at the dry skin passing process. Some mills are designated to run only dry or wet, others have either possibility. The dry process has some impact on the wear conditions of the rolls and an increase in wear, compared to the wet process can be assumed. 


\section{THE NEW BACKUP ROLL GRADE ASTI90X FOR SKIN PASS MILLS}

\subsection{Required Properties of Backup Rolls for Cold Mill Application}

Backup rolls in 4-hi and 6-hi mills have to provide certain properties in order to keep the rolling process as safe, constant and economical as possible. The achievement of

- good operational reliability,

- high rigidity,

- uniform hardness of barrel face,

- lowest hardness decrease within utilization area,

- high wear resistance,

- long campaigns,

- good surface conditions,

- high corrosion resistance and

- lowest tendency to dirt adhesion

outline the most important properties for the cold rolling mills with different impact on technical and/or economic aspects. Depending on the point of view of course some of the items are maybe more important than others, but we consider them all in our R\&D work even though a compromise is sometime necessary on certain aspects. However, the wear resistance has multi impact on operational reliability, the length of campaigns or amount of stock removal as well as on the surface conditions. Maintaining the profile and roughness are the key factors for this property.

\subsection{Comparison of available GP Backup Roll Grades for Cold Mill Applications}

Table 1. Chemistry of common CRM Backup roll grades [2]

\begin{tabular}{|c|c|c|c|c|c|c|c|c|c|c|}
\hline Quality & Type & Application & $\begin{array}{c}\text { C } \\
{[\%]}\end{array}$ & $\begin{array}{c}\text { Si } \\
{[\%]}\end{array}$ & $\begin{array}{l}\mathrm{Mn} \\
{[\%]}\end{array}$ & $\begin{array}{l}\mathrm{Cr} \\
{[\%]}\end{array}$ & $\begin{array}{l}\text { Mo } \\
{[\%]}\end{array}$ & $\begin{array}{c}\mathrm{Ni} \\
{[\%]}\end{array}$ & $\begin{array}{c}\mathbf{V} \\
{[\%]}\end{array}$ & $\begin{array}{c}W \\
{[\%]}\end{array}$ \\
\hline ASTIII80 & ICDP & Skin Pass & $\begin{array}{l}3.0- \\
3.5\end{array}$ & $\begin{array}{l}0.8- \\
1.5\end{array}$ & $\begin{array}{l}0.5- \\
1.5\end{array}$ & $\begin{array}{c}1.0- \\
2.0\end{array}$ & $\begin{array}{l}0.3- \\
0.8\end{array}$ & $\begin{array}{l}3.0- \\
4.5\end{array}$ & & \\
\hline AST80 & $2 \% \mathrm{Cr}$ & Tandem & $\begin{array}{c}0.6- \\
0.9\end{array}$ & $\begin{array}{l}0.4- \\
0.8\end{array}$ & $\begin{array}{l}1.5- \\
2.2\end{array}$ & $\begin{array}{c}1.6- \\
2.2\end{array}$ & $\begin{array}{l}0.3- \\
0.6\end{array}$ & $<0.8$ & & \\
\hline AST83 & $3 \% \mathrm{Cr}$ & $\begin{array}{l}\text { Tandem / } \\
\text { Skin Pass }\end{array}$ & $\begin{array}{l}0.6- \\
0.9\end{array}$ & $\begin{array}{l}0.4- \\
0.8\end{array}$ & $\begin{array}{l}0.8- \\
2.2\end{array}$ & $\begin{array}{c}2.5- \\
3.5 \\
\end{array}$ & $\begin{array}{l}0.5- \\
1.5\end{array}$ & $<0.6$ & & \\
\hline AST80X & $5 \% \mathrm{Cr}$ & $\begin{array}{l}\text { Tandem / } \\
\text { Skin Pass }\end{array}$ & $\begin{array}{l}0.2- \\
0.6\end{array}$ & $\begin{array}{l}0.4- \\
0.8\end{array}$ & $\begin{array}{l}0.4- \\
0.8\end{array}$ & $\begin{array}{c}4.0- \\
6.0\end{array}$ & $\begin{array}{l}0.8- \\
1.2\end{array}$ & $<0.8$ & $\begin{array}{l}0.4- \\
0.8\end{array}$ & \\
\hline ASTI80X & $\begin{array}{l}\text { Hicr- } \\
\text { Steel }\end{array}$ & Skin Pass & $\begin{array}{l}1.0- \\
1.6\end{array}$ & $\begin{array}{l}0.4- \\
0.8\end{array}$ & $\begin{array}{l}0.4- \\
1.0 \\
\end{array}$ & $\begin{array}{c}10.0- \\
14.0\end{array}$ & $\begin{array}{l}1.5- \\
4.5 \\
\end{array}$ & $\begin{array}{l}0.5- \\
1.5 \\
\end{array}$ & & \\
\hline ASTII80XX & $\begin{array}{l}\text { HiCr- } \\
\text { Iron }\end{array}$ & Skin Pass & $\begin{array}{c}2.5- \\
3.2\end{array}$ & $\begin{array}{l}0.4- \\
0.8\end{array}$ & $\begin{array}{l}0.6- \\
1.2\end{array}$ & $\begin{array}{c}16.0- \\
20.0\end{array}$ & $\begin{array}{l}0.5- \\
1.5 \\
\end{array}$ & $\begin{array}{l}1.0- \\
1.5\end{array}$ & $\begin{array}{l}0.2- \\
0.5\end{array}$ & \\
\hline ASTI90X & $\begin{array}{l}\text { CrMol- } \\
\text { Steel }\end{array}$ & $\begin{array}{c}\text { Skin Pass I } \\
\text { Tandem }\end{array}$ & $\begin{array}{c}0.6- \\
1.0\end{array}$ & $\begin{array}{l}0.8- \\
1.5\end{array}$ & $\begin{array}{l}0.5- \\
1.0\end{array}$ & $\begin{array}{c}6.5- \\
8.5\end{array}$ & $\begin{array}{l}2.0- \\
5.0\end{array}$ & $\begin{array}{l}0.5- \\
1.2\end{array}$ & $\begin{array}{l}0.4- \\
1.0\end{array}$ & $<3.0$ \\
\hline
\end{tabular}




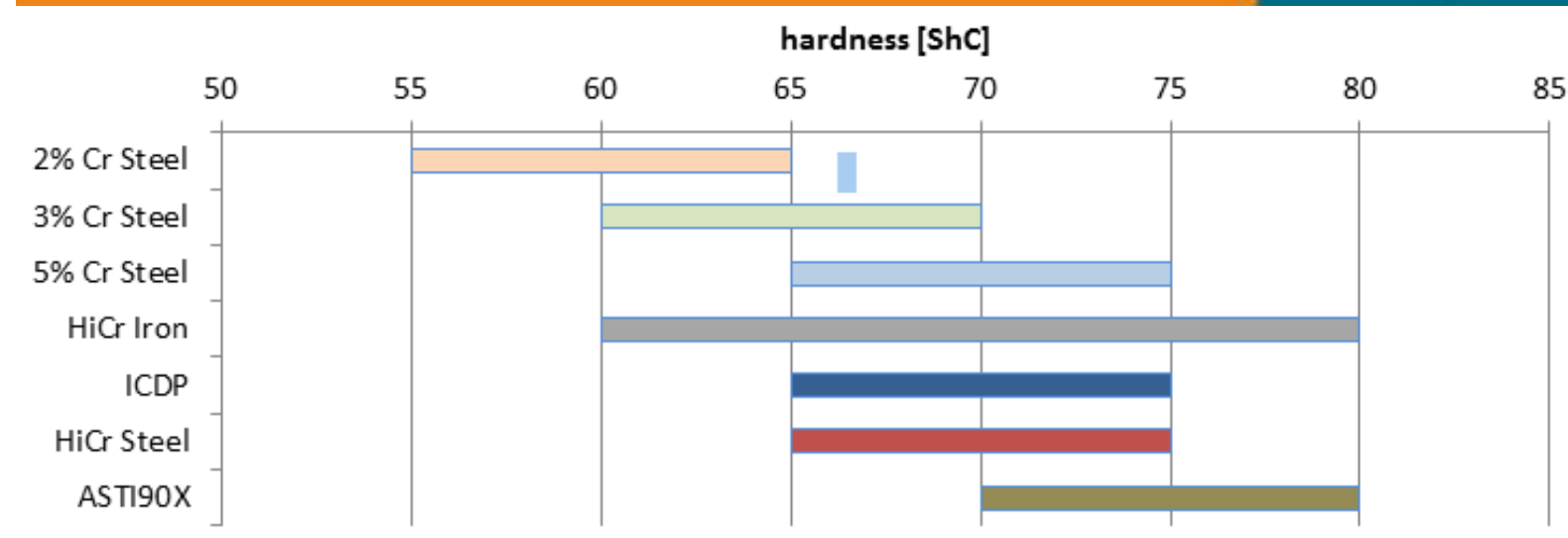

Figure 1. Hardness range of common Cold Mill backup roll grades.

\subsection{Properties of ASTI90X}

During the development of the new backup roll grade for the Skin-Pass and Cold Rolling applications the main focus was on wear and consequently shape stability, but the other important physical properties need to be controlled as well. The important strength and thermal properties of this material are given in Table II. A mentioned hardness range of 715-765 LE (Hardness Leeb) seems to be a wide spread, but the table shows the full hardness potential of the material, which may be needed for further applications. With a very established and good controlled heat treatment it is possible to achieve the hardness range adapted to the requirements an individual mill.

Due to the double pouring process, the shell material has practically constant hardness throughout the utilization area and will show almost no drop after every regrinding. This means a constant performance and the same rolling conditions throughout the entire life of the roll. Figure 2 indicate as an example the typical hardness gradient within the roll, when initial hardness is $750 \mathrm{LE}(\sim 77 \mathrm{ShC})$.

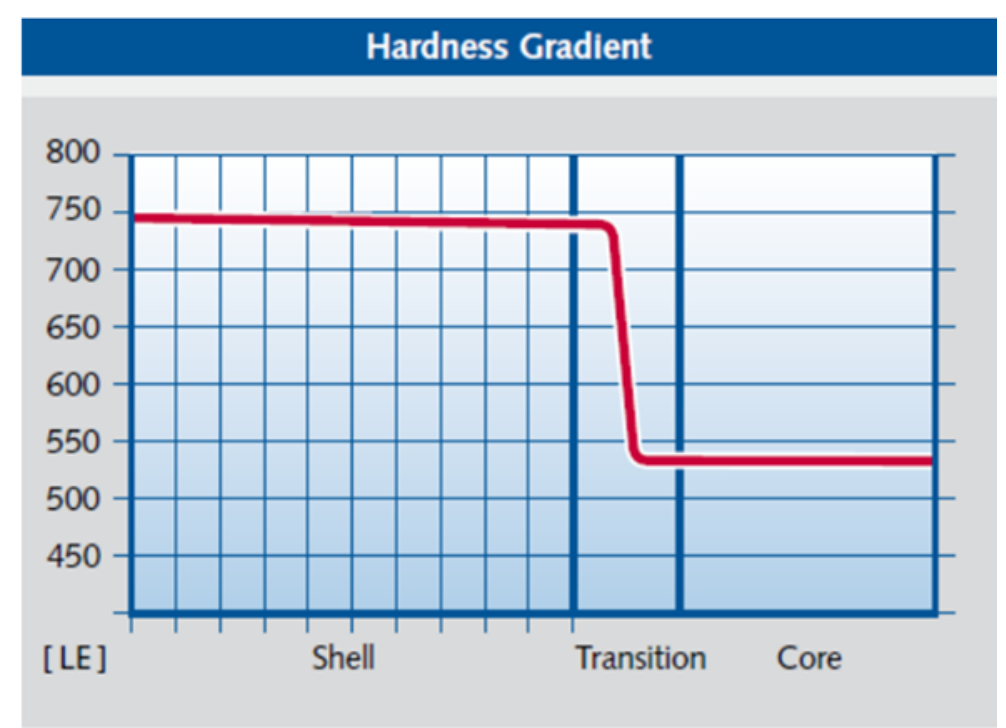

Figure 2. Hardness gradient of ASTI90X[3] 
Table 2. Physical properties of ASTI90X [4]

\begin{tabular}{|c|c|c|c|}
\hline \multicolumn{4}{|c|}{ Material Properties } \\
\hline & & Shell & Neck/Core \\
\hline Hardness & [LE] & $715-765$ & $470-595$ \\
\hline Hardness & [Shore C] & $70-80$ & $30-45$ \\
\hline Tensile Strength & [MPa] & 900 & 420 \\
\hline Young Modulus & [MPa] & 215.000 & 170.000 \\
\hline $\begin{array}{l}\text { Coefficient of Expansion } \\
20-100^{\circ} \mathrm{C}\end{array}$ & {$\left[* 10^{-6} / \mathrm{K}\right]$} & 11,0 & 12,5 \\
\hline Thermal Conductivity & {$\left[\mathrm{W} / \mathrm{m}^{*} \mathrm{~K}\right]$} & 20 & 32 \\
\hline Thermal Capacity & {$\left[\mathrm{KJ} / \mathrm{kg}^{*} \mathrm{~K}\right]$} & 450 & 575 \\
\hline Density & {$\left[\mathrm{kg} / \mathrm{m}^{3}\right]$} & 7.700 & 7.150 \\
\hline $\begin{array}{l}\text { Temperature Conductivity } \\
20-100^{\circ} \mathrm{C}\end{array}$ & {$\left[* 10^{-6} \mathrm{~m}^{2} / \mathrm{s}\right]$} & 5,80 & 7,80 \\
\hline
\end{tabular}

\subsection{Hardness versus Wear}

With a martensitic microstructure (Figure 3), having enclosed fine dispersed Carbides, the ASTI90X grade provide the improved wear properties. We found best conditions in backup roll / work roll application at a Skin Pass Mill, when the backup has an average target hardness of $75 \mathrm{ShC}$. Higher hardness values have some impact on the constancy of texturing of the work roll. Hence higher hardness, if applicable, will remain for other applications of this backup roll grade.
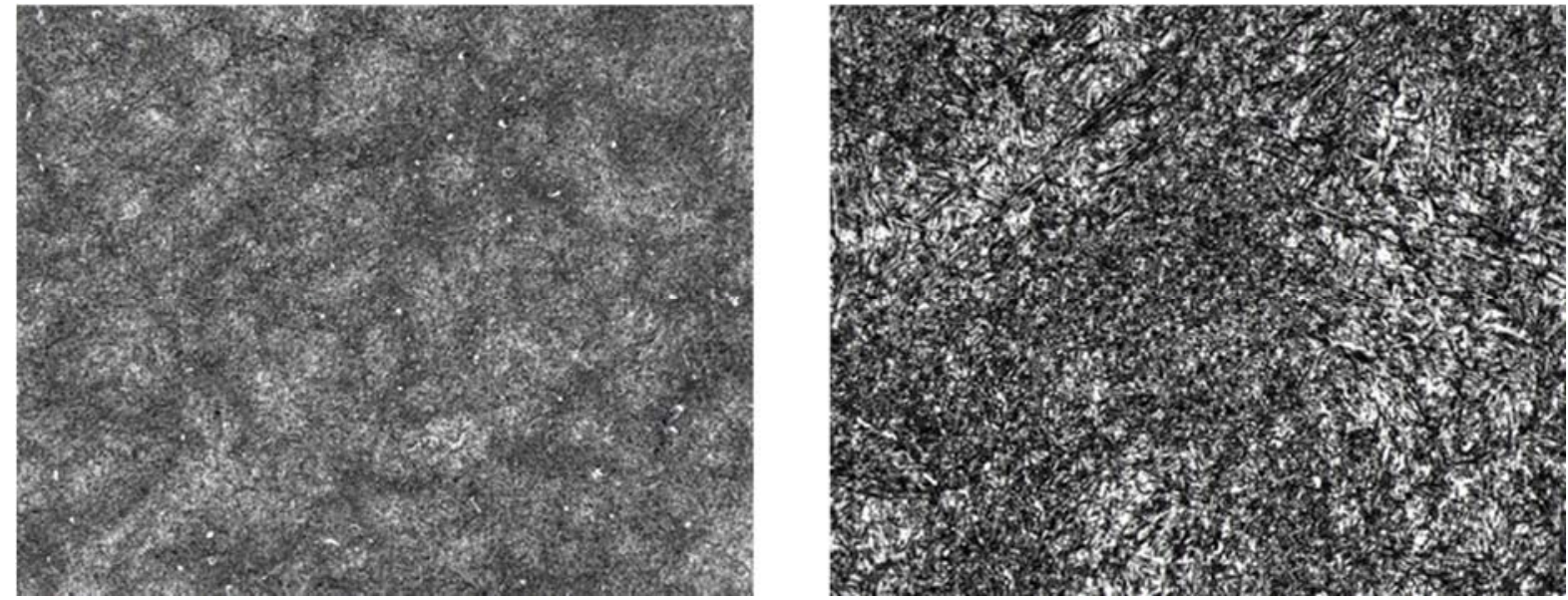

Figure 3. Microstructure of ASTI90X (left: x100, right: x500)

The hardness of a roll is a very important and in technical roll discussion maybe the most mentioned property. However, there is a relation between hardness and wear and of course some impact exists, but that is not a linear equation. The tribology of the roll application describes the interacting process of wear. Since the topography of textured work rolls, as often used in the Skin Pass process, lead to some increase of wear on the backup roll, wear in that application is commonly much higher than on rolls with same hardness without texturing. The achievement of the ASTI90X is, to provide without a significant increase of hardness, an exceeding improvement of abrasion ratio (Figure 3 and Figure 5). The improved abrasion ratio stands for higher wear resistance and hence less wear. 


\subsection{Wear Behavior of Backup Roll Grades}

In the laboratory, the wear behavior of roll materials can be figured out by measuring the abrasion ratio. The sample to be tested is machined to fit in the GP test stand as per Figure 4. With a constant force " $F$ ", the sample is pressed to a counter roll. This counter roll, taking the position of work roll in a mill stand, is driven by an electric motor and has higher hardness than the sample. Taking the weight of the sample before and after as well as the total number of revolutions enables the laboratory to work out the loss of weight per revolution ratio and to consider as indication for wear resistance. Conclusion of this test is: "The lower the loss of weight per revolution, the higher the wear resistance of the tested material". To match the conditions in the mills, the test stand can be run in wet and dry conditions.
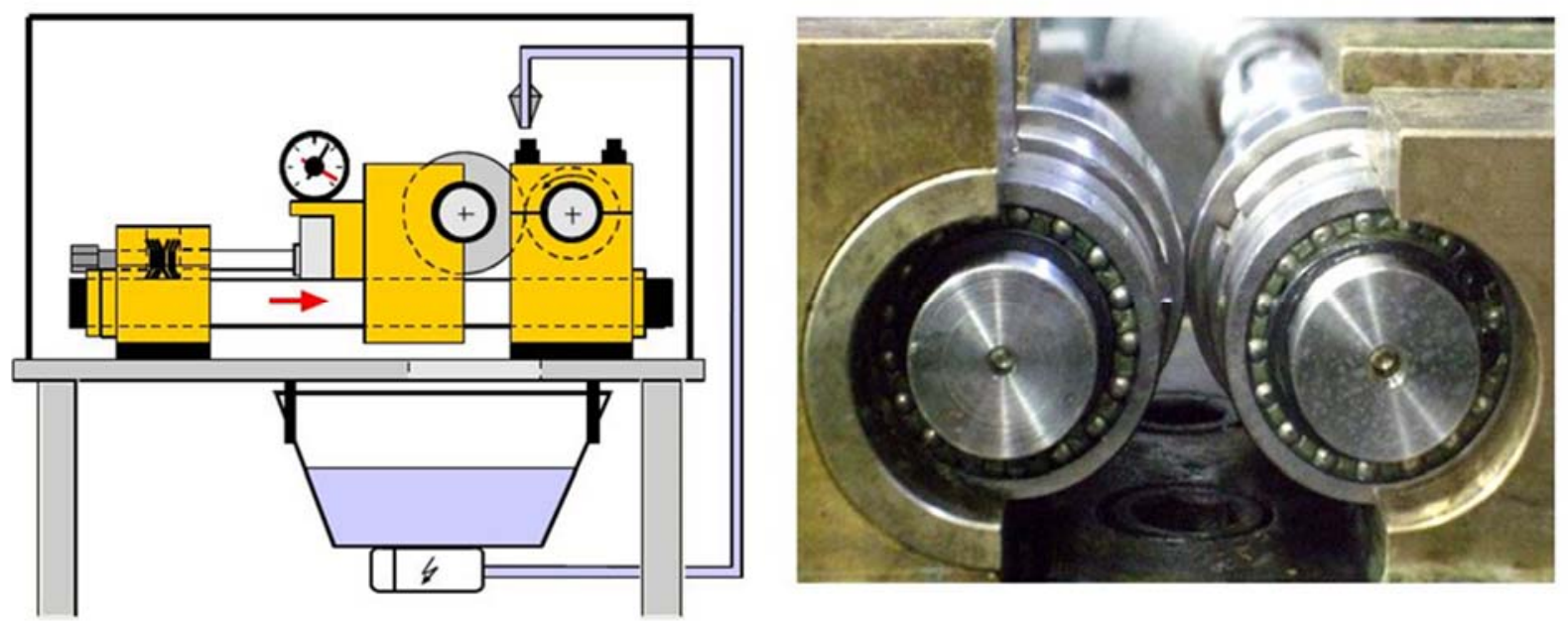

Figure 4. GP test stand for abrasion ratio

A single figure of the abrasion ratio has not too much of significance, but the comparison of alternative materials show the difference or improvement which can be achieved by enhanced roll grades (Figure 5). Using a $3 \% \mathrm{Cr}$ or a $5 \% \mathrm{Cr}$ steel backup roll grade is today very common for many Skin Pass mills, whereas the $2 \%$ $\mathrm{Cr}$ grade is obviously dropping in number of produced rolls. The abrasion ratio shown in the chart is giving one of the reasons for that. With a $50 \%$ lower abrasion ratio the $5 \% \mathrm{Cr}$ backup roll shows even in daily mill use an significant lower wear and hence better performance than the $2 \% \mathrm{Cr}$ grade. The superiority of ASTI90X to the common grades is proven by showing lowest abrasion ratio which is $75 \%$ less when compared to a $5 \% \mathrm{Cr}$ Steel.

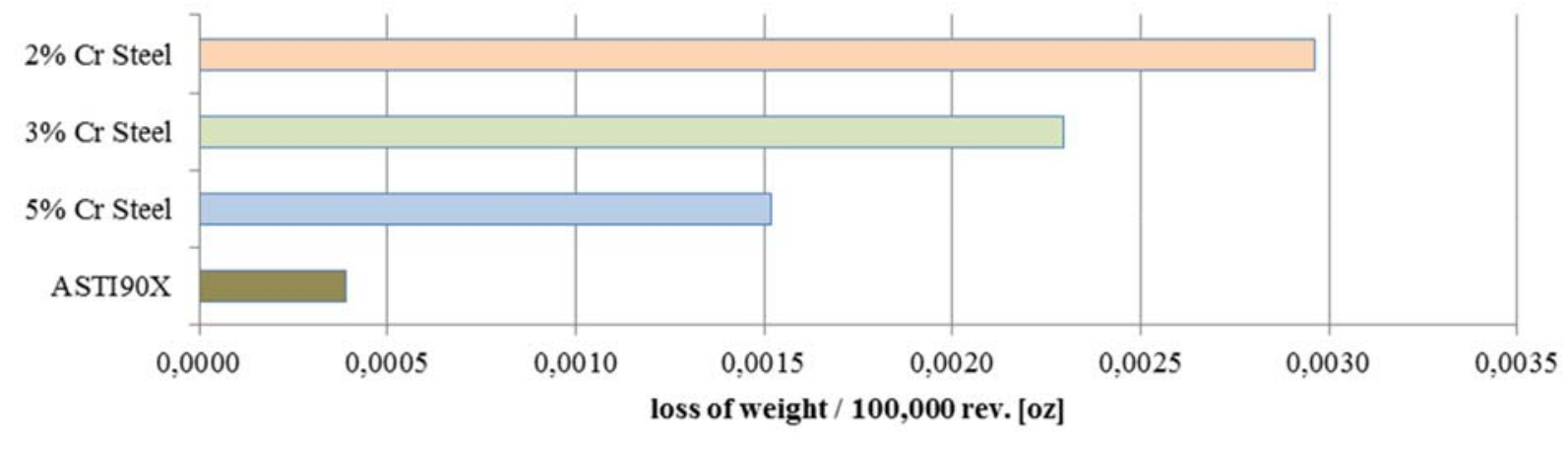

Figure 5. Abrasion ratio for some common roll grades 


\subsection{From Laboratory Test to Industrial Application}

Nobody likes to be a guinea pig but to verify the laboratory results and potential improvements, the roll manufacturer depend on (trial-) prepared mills. However, the R\&D work on new roll materials need to be proved in the industrial field, meaning the mill, after laboratory trials had been finished successfully. Only the success or lack of success in mill trials decide finally on further proceeding and whether a saleable product which provide improvement to the mills was found or not. Sometimes, and even in the case of ASTI90X, the in-field trials take quite a long time in order to get really solid results. The quite long lifetime of those rolls claim some patience. To convince a mill doing the very first runs with an all new roll grade and in case of success provide all the details may be a challenge, but we are quite happy that already several customers placed orders on this grade with GP, after the first rolls have finished their entire life according to expectations. We see the confidential treatment of received customer details and knowledge as a basis of relationship. Our companies guiding principles are -innovation - flexibility and - reliability.

\subsection{Wear Behavior and Roll Performance}

The roll performance has some impact on the total roll costs and hence money to spend for consumables at a mill. To achieve highest possible performance within the mill is a challenge for all involved, the mill, the roll shop and the roll supplier. In addition to the product and operational influence on performance, the rolls are a big factor as well. Reduced wear may lead to higher performance but sometimes even offer also more reliability of the process.

The new roll grade ASTI90X achieved following performance increase in a 58 Inch two stand Skin-Pass Mill (DCR Mill) for Tinplate, working 100\% with wet skin pass agent:

- with $5 \%$ Cr backup roll

- with ASTI90X backup roll average of about 30 tons/ $0.001 "$ average of about 85 tons/0.001" (Figure 9.)

If we take the 30 tons $/ 0.001$ " as baseline, the improvement rate is almost 3 times. Of course such an increase of performance will not achieved in any case or any mill, but the potential of this grade can be considered as proven:

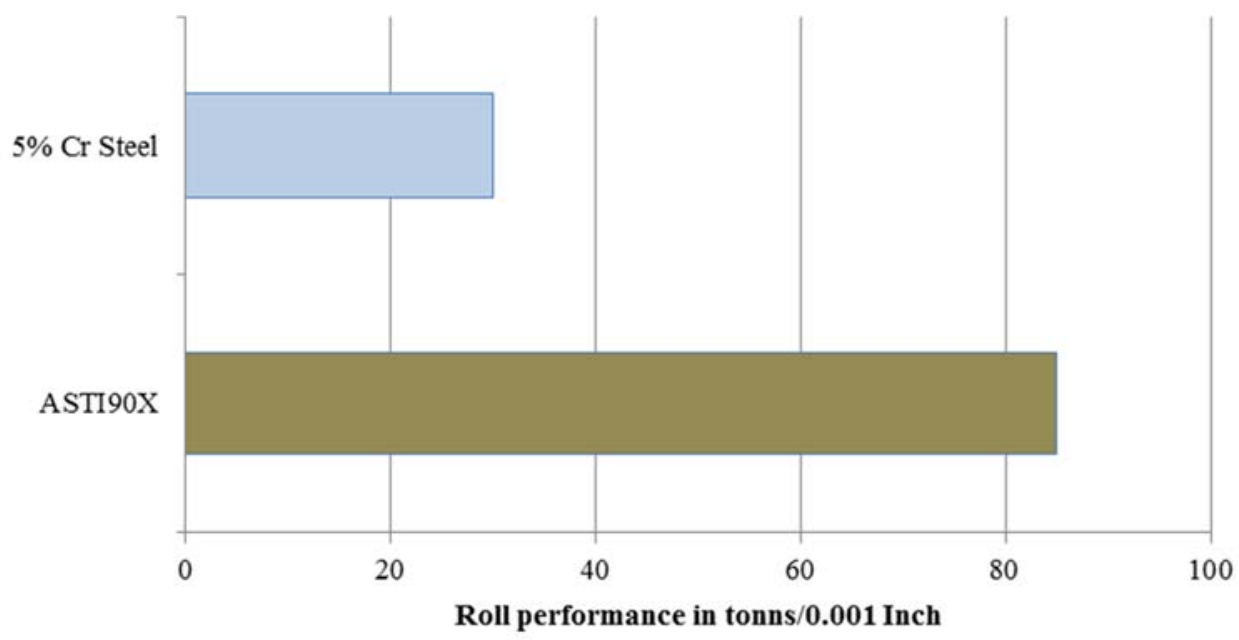

Figure 6. Performance improvement with ASTI90X 


\subsection{Wear Behavior and Impact on Contact-Load}

For all rolls the specific contact load need to receive serious attention. In the area, where a work roll touches a backup roll, a specific contact load applies. This load is for some reason not equally distributed. This means that there isn't same pressure at every contact point. Among others, the initial profile of the two touching rolls affects the load distribution. Furthermore, the profile of the rolls is changing during the campaign, thus the distribution of load even changes. With an increase of wear caused by the rolling process even the maximum specific load increases.

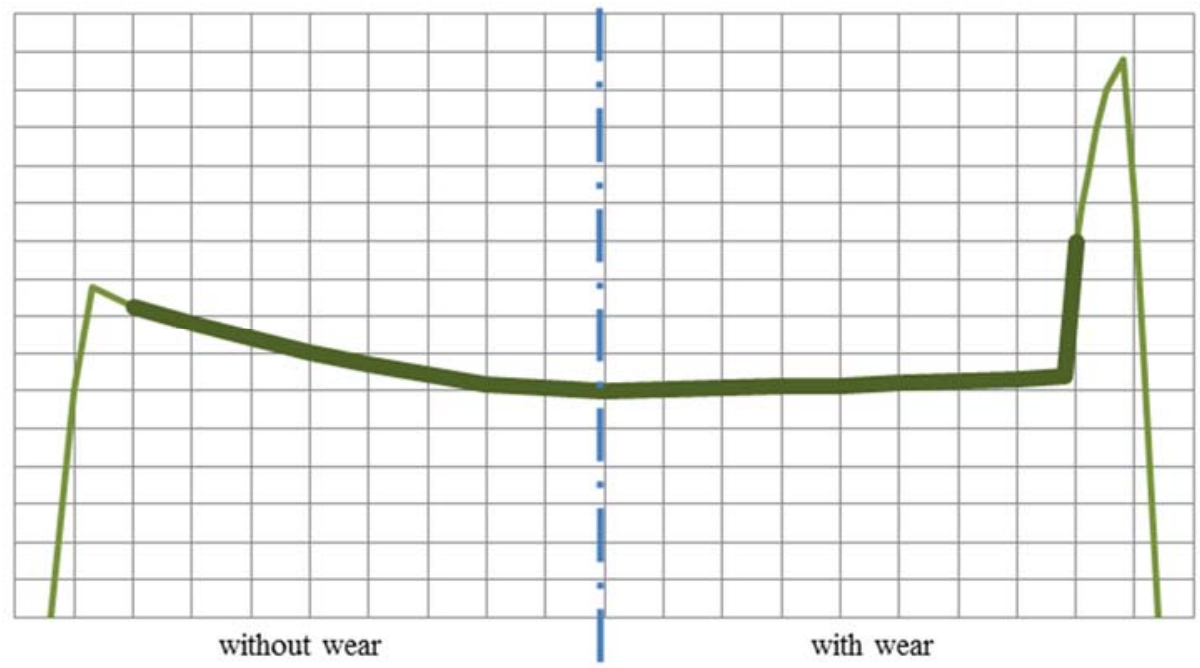

Figure 7. Effect of wear on the contact load distribution on backup roll [5]

Figure 7 shows simplified the typical load distribution of a backup roll at the very beginning of the campaign (left) and after roll is worn at the end of the campaign (right).When the $x$-axis shows the length of barrel face, the $y$-axis display the specific contact load. On a worn out backup roll (right half) occur a significantly higher contact load close to the end of barrel face. The operational reliability is negative affected and in worst case a spalling of the backup roll can happen when operating at or beyond critical limits.

When the grade ASTI90X provide in comparison to common roll grades a much higher wear resistance, consequently the initial profile of the roll will be kept for a longer time. With the advantage of roll profile constancy, the mill can make the most of it by running longer campaigns with constant product quality or improving the operational reliability.

\section{OUTLOOK AND FURTHER EVOLUTION OF ASTI90X}

So far the ASTI90X in evolution stage one is produced for the Cold-Mill applications with ductile Iron core and necks. Mechanical properties of ASTI90X with iron necks are particularly suitable and safe for the separating force of cold mill applications like Inline Skin Pass Mills, Offline Skin Pass Mills or Double Cold Reduction Mills. In order to make the field of applications much wider, the evolution two of this grade is already under investigation: with a steel core and necks the admissible force on the backup roll can be much higher. First results in Cold Mill make us feel confident, that more applications (e.g. last stand of a tandem cold mill) can participate of the 
improvement. The market launch for that next evolution is not yet scheduled but will be communicated when it is.

\section{CONCLUSIONS}

The next milestone for Cold Mill backup roll grades is definitively set with the grade ASTI90X. The improvement factor on performance of about three is almost incredible. Getting beyond the performance increase even the improvement of roll profile constancy and of operational reliability shall not be underestimated. The combination of available production capabilities, process advantages and opportunities as well as the experience in Hot Rolling Mills as well as in Cold Rolling Mills was put into one basket. Trials in laboratory supported and approved by in-field trials at customer site helped a lot to find a key for solutions. The initial results with ASTI90X motivate us for further investigation and trials on other applications. Without running an own mill, the development of new roll grades depend for roll manufacturer on mills which are prepared for improvement and trials.

\section{REFERENCES}

1 Philippe Wolper, "Steel: the sustainable packaging solution", The Association of European Producers of Steel for Packaging

2 Andreas Cestonaro, "GP Cold Rolling Rolls", VDEh FA Kaltband, Essen Germany September 2012

3 Gontermann-Peipers GmbH, "Quality Data Sheet \#22, ASTI90X"

4 Gontermann-Peipers GmbH, "Quality Data Sheet \#22, ASTI90X"

5 Gontermann-Peipers GmbH, "Take Care of Your Backup Roll” 